\title{
A Twin Spool Engine Emulator for the Study of Power Exchange Idea
}

\author{
Hossein Balaghi Enalou, Mohamed Rashed, Ponggorn Kulsangcharoen, Shajjad Chowdhury, Serhiy Bozhko \\ Department of Electrical and Electronic Engineering, Faculty of Engineering, \\ University of Nottingham, University Park, Nottingham, UK, NG7 2RD.Email: eexhb3@nottingham.ac.uk
}

\begin{abstract}
The More Electric Aircraft (MEA) engine, with electrical machines on both HP and LP shafts, makes it possible to transfer power electrically from one spool to another. Preliminary results have shown considerable improvement in turbofan performance in terms of fuel consumption, engine stability and compatible thrust with flight mission. In order to prove the concept of power exchange between shafts, it is essential to design a subscale system to emulate the more electric engine (MEE). This paper describes the layout of the experimental system to emulate the MEE to study the idea of power exchange between shafts through a single dc bus architecture.
\end{abstract}

Keywords-Engine Emulator, Power Exchange, More Electric Aircraft (MEA)

\section{INTRODUCTION}

The concept of the More Electric Aircraft (MEA) has resulted in introduction of various new technologies via advancements of on-board electrification. Successful achievement of these innovative ideas will results in further reduction of aircraft weight, equipment volume, overall fuel burn and improved efficiency of aircraft systems, hence less environmental impact and greener aviation.

One of the main areas of the research for the MEA is mounting a generator on the Low Pressure (LP) shaft in addition to the starter/generator mounted on the High Pressure (HP) shaft of the engine [1].

Given that there are electrical machines on both LP and HP shafts, the authors of this paper have introduced the idea of power exchange between shafts in a single dc bus architecture in [2]. In this architecture, the electrical machines are connected to a single dc bus through bidirectional convertors which helps bidirectional transfer of power between the LP and HP shafts. The direction of power circulation, depending on flight mission and optimum performance operation of the engine, can be either from the LP shaft to the HP shaft, or from the HP shaft to the LP shaft or power sharing between the LP and HP shafts for the Electric Power System (EPS) of the aircraft. Preliminary results in [2] show great benefits in terms of fuel consumption, engine stability and compatible thrust with flight mission at various flight scenarios.

At the initial stage, in order to prove the concept and demonstrate the practicality of this idea, it is essential to design a subscale system to emulate the More Electric Engine (MEE). The engine emulator would enable better understanding and preliminary analysis of the idea of power circulation between shafts. Accordingly, it can closely resemble the overall electrical energy generation system under various operating conditions experimentally without the need to operate the real engine. Therefore, aspects such as electric machine and power converter topologies, electric power quality, effect of fault scenarios on the performance of the new architecture, regeneration management, as well as the overall system safety, reliability and availability will be thoroughly investigated.

Such an integrated power center suggest optimized operation according to the Engine Operation Mode (EOM) with simultaneous minimization of overall weight and volume, increasing the overall system efficiency, as well as improving its reliability and maintainability.

In the literature, aero-derivative gas turbine engine emulation has been widely implemented in the Hardware in the Loop (HIL) environment [3-6]. HIL simulation provides the ability to study the system in a safe and controlled fashion [7].

In this paper, an HIL simulation framework is developed for the power system of the aircraft. This will consider the engine as a part of the overall electrical energy generation system, together with the driven generators, one from the LP shaft and another one from the HP shaft, and the power electronic convertors for controlling the power circulation.

For this purpose, a twin spool turbofan real-time model is run by the dSPACE control system used for the Hardware in the Loop (HIL) implementation. The engine's HP and LP shaft speed set-points, generated by dSPACE, are sent to two induction motor drives to mimic the speed-torque characteristic of the turbofan shafts. The drives are mechanically coupled with the engine LP and HP electrical machines. Power can be transferred between engine shafts through the DC bus.

The amount of power required to be transferred to achieve some benefits on the engine performance is $500 \mathrm{~kW}$ [2]. While the emulator shaft power is designed to be $50 \mathrm{~kW}$. For this reason the emulator rig data are scaled up in order to communicate with the dSPACE, implementing similarity analysis.

The paper is organized as follows: Section II gives a brief introduction to the idea of electrical power transfer between engine shafts. Section III describes the emulation system. In Section IV, the theory of similarity is exemplified. Section V presents the engine model and its control system used for the emulator and Section VI concludes the paper.

\section{Electric Power TRANSFER BETWEen SHAFtS}

The LP and HP shafts of the engine are not connected mechanically, however their speeds are thermodynamically 
coupled which imposes certain operational constraints specifically at engine low speed settings. For this reason, there will be a great interest in controllable power transfer between shafts to relatively decouple shaft speeds and improve engine performance.

MEA can provide this possibility by the electrical machines connected to both LP and HP shafts. A well-known architecture for the MEA power system is the single dc bus architecture, widely elaborated in the literature [8-10] within which the machine outputs are connected to the dc bus through bidirectional convertors, as shown in Fig. 1. This provides the opportunity to circulate dynamically controllable power between shafts through the electrical machines.

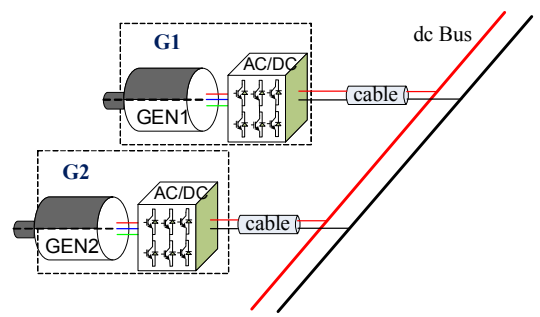

Fig. 1. Configuration of single dc bus multi-source EPS

The power circulation between shafts can simply be expressed as below:

$$
T_{E L P} \times \omega_{L P}+T_{E H P} \times \omega_{H P}+P_{E P S}+P_{\text {loss }}=0
$$

where $T_{E H P}$ and $T_{E L P}$ are the torques of the electrical machines connected to the HP and LP shafts with the corresponding speeds of $\omega_{H P}$ and $\omega_{\mathrm{LP}} . P_{E P S}$ is the electrical load power on the dc bus and $P_{l o s s}$ is the power loss of the system.

\section{GAS TURBINE ENGINE EMULATION SySTEM}

To investigate the power transfer effect between the HP and LP shafts on the aircraft engine performance, the aircraft engine emulator system is constructed. The block diagram of the emulator system is shown in Fig. 2 and it comprises of two Oswald induction machines with two front-end drives of $40 \mathrm{~kW}$ and a dSPACE Rapid Control Prototyping (RCP) system. The system can deliver peak power of $50 \mathrm{~kW}$ per shaft. The drives control the induction machines to mimic the $\mathrm{HP}$ and LP engine characteristics for wide speed range from 10000 to $20000 \mathrm{rpm}$.

On the emulator test bed, as illustrated in Fig. 3, a Permanent Magnet Synchronous Machine (PMSM) and a SwitchedReluctance Machine (SRM) connected to the LP and HP shafts' drives respectively. The outputs of both machines are connected to the aircraft DC power system through bidirectional power convertors.

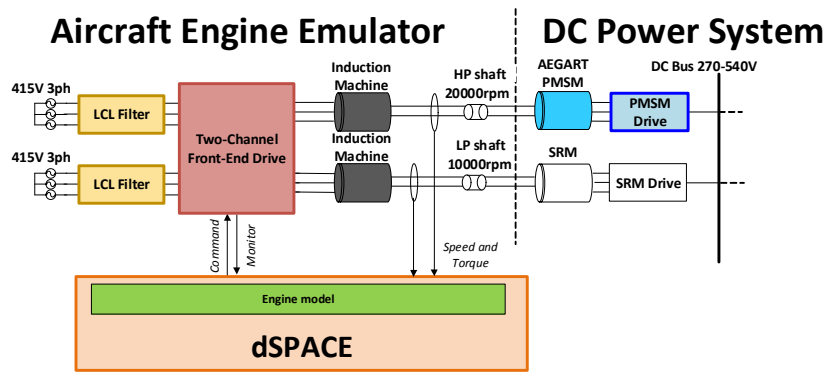

Fig. 2. The emulator system block diagram

The dSPACE control platform is used for the implementation and online simulation of the complex nonlinear aircraft engine model. The engine model in simulink is automatically downloaded into the dSPACE to be calculated in real time. The engine model receives torque measurements from both shafts and produces the speed references to the emulator drive system. The drives have their own fast speed control loop to guarantee excellent tracking of the reference speed provided by the dSPACE system.

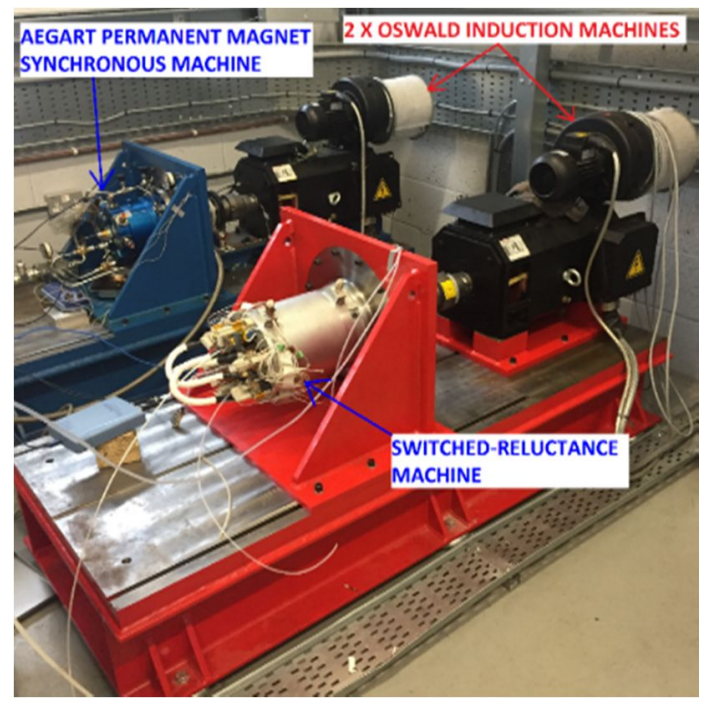

Fig. 3. The emulator HP and LP testbeds

\section{SIMILARITY ANALYSIS}

For the studied real engine in [2], the amount of power transfer between shafts was around $500 \mathrm{~kW}$. However, the nominal power of electrical machine for the designed emulator is $50 \mathrm{~kW}$. In this case either the engine model or the electrical system should be scaled to make the emulation compatible with the real system performance. Due to the complexity of the engine model, the electrical power system is scaled using similarity rules in [11]. To exemplify, the PMM is scaled as explained below.

The dynamic equations for PMM machines in dq frame are:

$$
L_{d} \frac{d i_{d}}{d t}=v_{d}-R i_{d}+L_{q} p \omega_{r} i_{q}
$$




$$
L_{q} \frac{d i_{q}}{d t}=v_{q}-R i_{q}-\left(L_{d} p \omega_{r} i_{d}+\varphi_{m} p \omega_{r}\right)
$$

where: $v_{d}, v_{q}, i_{d}$ and $i_{q}$ are the $\mathrm{d}$ and q-axis voltage and current components and the positive current is the current following into the machine. $R_{s}, L_{d}$ and $L_{q}$ are the stator resistance and inductances, $\omega_{r}$ is the mechanical rotor speed, $p$ is the number of pole pairs and $\varphi_{m}$ is the permanent magnet flux.

Dividing equations (2) and (3) respectively by $R i_{d}$ and $R i_{q}$, the equations below are obtained;

$$
\begin{aligned}
& 1+\frac{L_{d}}{R i_{d}} \frac{d i_{d}}{d t}-\frac{v_{d}}{R i_{d}}-\frac{L_{q} p \omega_{r} i_{q}}{R i_{d}}=0 \\
& 1+\frac{L_{q}}{R i_{q}} \frac{d i_{q}}{d t}-\frac{v_{q}}{R i_{q}}+\frac{L_{d} p \omega_{r} i_{d}+\varphi_{m} p \omega_{r}}{R i_{q}}=0
\end{aligned}
$$

Considering two PMM, since the phenomena are similar, the parameters can be related by scale factors $(m)$ as below:

$$
t_{1}=m_{t} t_{2}, R_{1}=m_{R} R_{2}, \ldots
$$

The same is applied to $L, p, \varphi_{m}, v_{d}, v_{q}, i_{d}$ and $i_{q}$.

By substituting (7) into (5) and (6), the equations below are obtained:

$$
\begin{aligned}
& 1+\frac{m_{L}}{m_{R} m_{t}} \frac{L_{d_{2}}}{R_{2} i_{d_{2}}} \frac{d i_{d_{2}}}{d t_{2}}-\frac{m_{L_{q}} m_{p} m_{\omega_{r}} m_{i_{q}}}{m_{R} m_{i_{d}}} \frac{L_{q_{2}} p_{2} \omega_{r_{2}} i_{q_{2}}}{R i_{d}}- \\
& \frac{m_{v_{d}}}{m_{R} m_{i_{d}}} \frac{v_{d_{2}}}{R_{2} i_{d_{2}}}=0
\end{aligned}
$$

The same is applied for q axis equation. Since equations (5) and (6) are homogeneous, from equations (8), it can be found that the scale factors are related as below:

$$
\begin{aligned}
& 1=\frac{m_{v_{d}}}{m_{R} m_{i_{d}}}=\frac{m_{L_{q}} m_{p} m_{\omega_{r}} m_{i_{q}}}{m_{R} m_{i_{d}}}=\frac{m_{L}}{m_{R} m_{t}}=\frac{m_{v_{q}}}{m_{R} m_{i_{q}}}= \\
& \frac{m_{L_{d}} m_{p} m_{\omega_{r}} m_{i_{d}}}{m_{R} m_{i_{q}}}=\frac{m_{\varphi_{m}} m_{p} m_{\omega_{r}}}{m_{R} m_{i_{q}}}
\end{aligned}
$$

Replacing the scale factors by the ratios of corresponding parameters, the relation below is obtained:

$$
\frac{v_{d_{1}} / v_{d_{1}}}{\left({ }^{R_{1} / R_{2}}\right)\left({ }^{\left.i_{d_{1}} / i_{d_{1}}\right)}\right.}=1, \ldots
$$

In the notation for general similarity criteria:

$$
\begin{aligned}
& \pi_{1}=\frac{v_{d}}{R i_{d}}, \pi_{2}=\frac{v_{q}}{R i_{q}}, \pi_{3}=\frac{L}{R t}, \pi_{4}=\frac{L p \omega_{r} i_{q}}{R i_{d}}, \\
& \pi_{5}=\frac{\varphi_{m} p \omega_{r}}{R i_{q}}
\end{aligned}
$$

Table I shows the specifications of the PMM used on the emulator rig (AEGART [12]) and a typical $500 \mathrm{~kW}$ PMM.

Table I Specifications of PMMs

\begin{tabular}{|c|c|c|c|}
\hline Parameter & Symbol & Model (1) & Experiment (2) \\
\hline Power rating & $\mathrm{P}$ & $500 \mathrm{~kW}$ & $50 \mathrm{~kW}$ \\
\hline Phase resistance & $R_{s}$ & $0.38 \mathrm{~m} \Omega$ & $1.06 \mathrm{~m} \Omega$ \\
\hline Machine inductance & $L_{d}, L_{q}$ & $50 \mu \mathrm{H}$ & $99 \mu \mathrm{H}$ \\
\hline $\begin{array}{c}\text { Permanent magnet } \\
\text { flux linkage }\end{array}$ & $\varphi_{m}$ & $0.060 \frac{\mathrm{Vs}}{\mathrm{rad}}$ & $0.036 \frac{\mathrm{Vs}}{\mathrm{rad}}$ \\
\hline $\begin{array}{c}\text { Number of } \\
\text { pole pairs }\end{array}$ & $p$ & 8 & 3 \\
\hline Speed & $\omega$ & $12000 \mathrm{rpm}$ & $32000 \mathrm{rpm}$ \\
\hline DC bus voltage & $V_{D C}$ & $540 \mathrm{volt}$ & $270 \mathrm{volt}$ \\
\hline
\end{tabular}

The dependent values must be taken at corresponding moments of time. In the present case, those moments of time are in a way that:

$$
t_{1}=1.4 t_{2}
$$

Which means $50 \mathrm{~kW}$ machine is 15 times faster than $500 \mathrm{~kW}$ machine. If machine independent parameters are assumed not to change by time, then the relations below between two machines are obtained:

$$
\frac{v_{d_{1}}}{i_{d_{1}}}=0.36 \frac{v_{d_{2}}}{i_{d_{2}}}, \frac{v_{q_{1}}}{i_{q_{1}}}=0.36 \frac{v_{q_{2}}}{i_{q_{2}}}, \ldots
$$

\section{ENGINE MODEL}

The Inter Component Volume (ICV) method has been implemented in the MATLAB/SIMULINK environment to develop a modulated multi-spool turbofan model in [13] which has been verified in [14].

Fig. 4 illustrate the arrangement of the engine component where $\dot{m}, T, p, \omega$ and $P$ are mass flow, temperature, pressure rotor speed and power respectively.

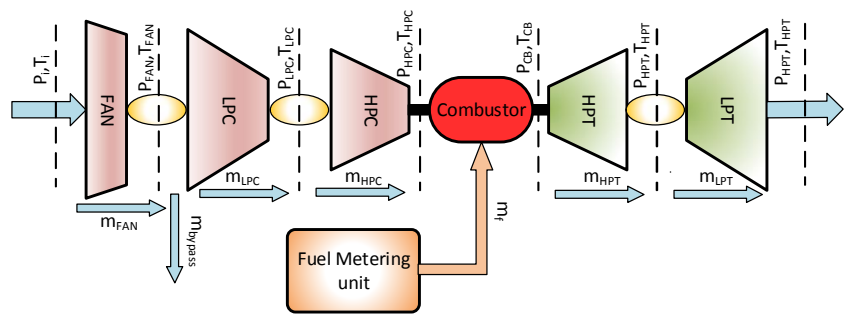

Fig. 4. Illustration of Jet-engine 0-dimensional component level model

A bump-less override control structure has also been implemented for the turbofan with limit controllers for overtemperature, surge and bleeding pressure for the Environmental Control System (ECS).

Shaft dynamics for the real system can be expressed as below:

$$
\begin{aligned}
& T_{H P T}-T_{H P C}-J_{H P} \dot{\omega}_{H P}=T_{E H P} \\
& T_{L P T}-T_{F A N}-T_{L P C}-J_{L P} \dot{\omega}_{L P}=T_{E L P}
\end{aligned}
$$

where $\mathrm{T}_{\mathrm{HPT}}$ and $\mathrm{T}_{\mathrm{LPT}}$ are the generated torque by the High and Low Pressure Turbines (HPT and LPT) respectively, $\mathrm{T}_{\mathrm{HPC}}$ and $\mathrm{T}_{\mathrm{LPC}}$ are the consumed torque by the High and Low Pressure Compressors (HPC and LPC) respectively.

For the application in the emulator, component modules shown in Fig. 4Fig. 5 are solved online to provide $T_{H P T}, T_{L P T}$, $T_{H P C}$ and $T_{L P C}$ for the LP and HP shaft modules. The outputs of the engine model to the drives are LP and HP shafts realtime speed references while the inputs to the engine model are torque values of SR and PM machines corresponding to LP and HP shafts respectively. $\mathrm{T}_{\mathrm{E} H \mathrm{P}}$ and $\mathrm{T}_{\mathrm{E} L \mathrm{P}}$ are the signals from the torque sensors on emulator shafts after scaling. 


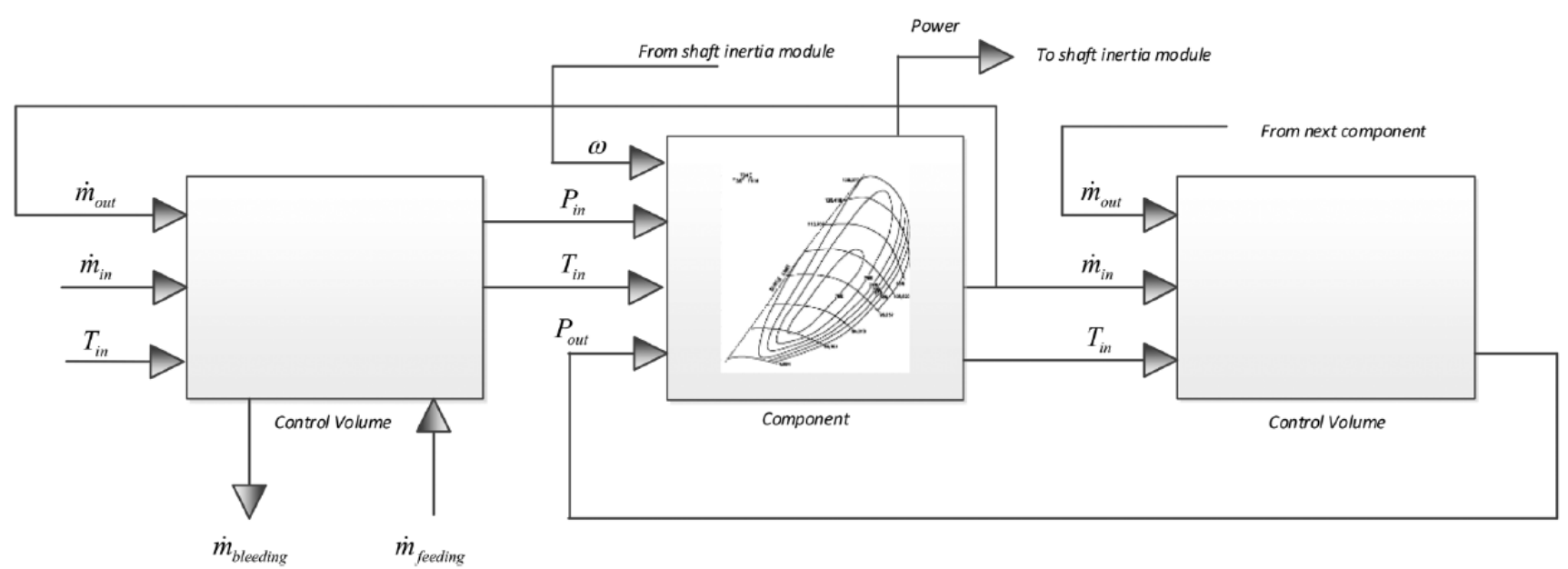

Fig. 5. Structure of gas turbine model component modules

The real-time outputs of shaft dynamic modules after solving equations (14) and (15) are the HP shaft speed, $\omega_{H P}$, and the LP shaft speed, $\omega_{L P}$, which, after scaling, are the speed references for the drives on the emulator rig.

\section{REAL-TIME EMULATION}

As discussed in section IV, the electrical machines are scaled down from $500 \mathrm{~kW}$ to $50 \mathrm{~kW}$ as shown in Fig. 6.

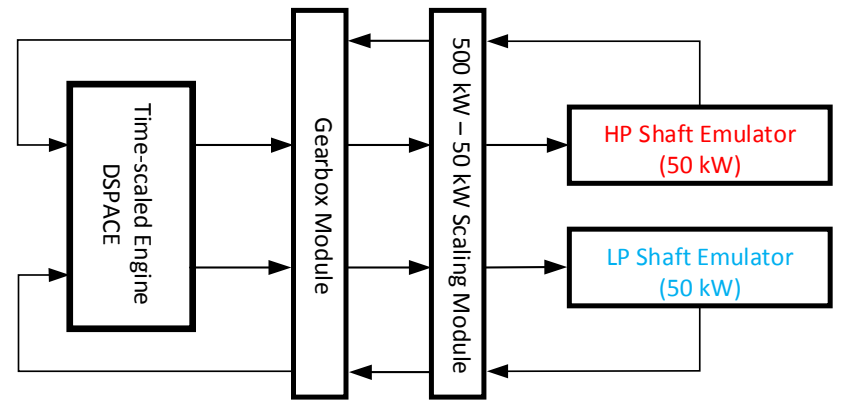

Fig. 6. Schematic of emulator rig simulation modules

Engine shaft emulators are run in real-time and the DSPACE runs the engine model in real time as well,while based on equation (12) the engine model simulation time should be scaled. If the real time is symbolled as $t$, since the emulator rigs run at real time then, $t_{2}=t$ and $t_{1}=m_{t} t$.

For the ICV engine modelling approach, the state space differential equation of the model is:

$$
\begin{aligned}
& \frac{d X_{1}}{d t_{1}}=A\left(X_{1}\right) \cdot X_{1}\left(t_{1}\right)+B\left(X_{1}\right) \cdot U_{1}\left(t_{1}\right) \\
& Y_{1}=C\left(X_{1}\right) \cdot X_{1}\left(t_{1}\right)+D\left(X_{1}\right) \cdot U_{1}\left(t_{1}\right)
\end{aligned}
$$

where $\mathrm{X}$ is the states' vector, $\mathrm{U}$ is the model input and $\mathrm{Y}$ is the model output and A, B, C and D are state dependent matrixes.
For the other similar process system with inputs, $U_{2}$, since the processes are similar,

$$
X_{1}=m_{X} X_{2}, U_{1}=m_{X} U_{2}, t_{1}=m_{t} t
$$

Substituting (17) into (16), the state space equation in real time will be:

$$
\begin{aligned}
& \frac{m_{X} d X_{2}}{m_{t} d t}=A\left(m_{X} X_{2}\right) \cdot m_{X} X_{2}(t)+B\left(m_{X} X_{2}\right) \cdot m_{U} U_{2}(t) \\
& m_{Y} Y_{2}=C\left(m_{X} X_{2}\right) \cdot m_{X} X_{2}(t)+D\left(m_{X} X_{2}\right) \cdot m_{U} U_{2}(t)
\end{aligned}
$$

As stated before, the engine model is preferred not to be scaled, for which:

$$
m_{X}=m_{U}=m_{Y}=1
$$

while the states corresponding to shaft speeds will be scaled separately with scale factor, $M_{N}$ and the torque inputs to the engine will be scaled with the scale factor, $M_{T}$, to match real engine performance. As a result the state space equations will be scaled only in time as below:

$$
\begin{aligned}
& \frac{d X_{2}}{d t_{2}}=m_{t}\left(A\left(X_{2}\right) \cdot X_{2}(t)+B\left(X_{2}\right) \cdot U_{2}(t)\right) \\
& Y_{2}=C\left(X_{2}\right) \cdot X_{2}(t)+D\left(X_{2}\right) \cdot U_{2}(t)
\end{aligned}
$$

In order to implement the time scaling shown in equation (20) in the ICV approach, the time scale factor block, $m_{t}$, is added before each state derivative in Simulink as shown in Fig. 7.

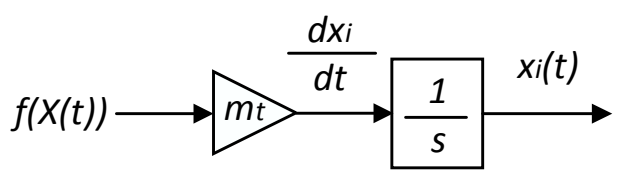

Fig. 7. Time scale block for Simulink state blocks

$X$ is the state vector and $x_{i}$ is the corresponding state. Given that shaft speeds are states as well and $J$ is the shaft inertia of 
the engine, applying the time scale $m_{t}$ basically can be interpreted as that the inertia of the shafts are modified to $\frac{J}{m_{t}}$. It should be noted that model inputs which are a function of time such as throttle, should be scaled in time as well.

\section{SIMULATION RESULTS}

This section presents the performance plots of key dynamic and steady-state tests such as engine acceleration and deceleration and power offtake form engine shafts by generators.

Thermodynamic maps from GASTURB have been used to model a two-spool high bypass ratio $(\mathrm{BPR}=8)$ unmixed flow $140 \mathrm{kN}$ turbofan.

IM and PMM have been modeled in dq frame with a functional model for their convertors, while a switching model in PLECS has been implemented for the SRM in Simulink environment.

\section{A. Power off-take emulation}

For the existing EPS architectures with the starter/generator connected to the HP shaft, the amount of power off-take for a $140 \mathrm{kN}$ turbofan is around $50 \mathrm{~kW}$. Basically, AEGART has been designed to be mounted on the HP shaft of an aircraft engine HP shaft with approximately the same thrust rate as a starter/generator with the gear ratio of 1 .

In order to study the performance of AEGART on the engine for which it is designed, the HP emulator rig can be used while $m_{t}=1$.

Fig. 8 shows the speed tracking performance in which induction machine resembles the behavior of the engine shaft for the coupled PMM for a $40 \%$ drop in throttle (at $\mathrm{t}=5 \mathrm{~s}$ ) and then a rise at $(\mathrm{t}=15 \mathrm{~s})$.

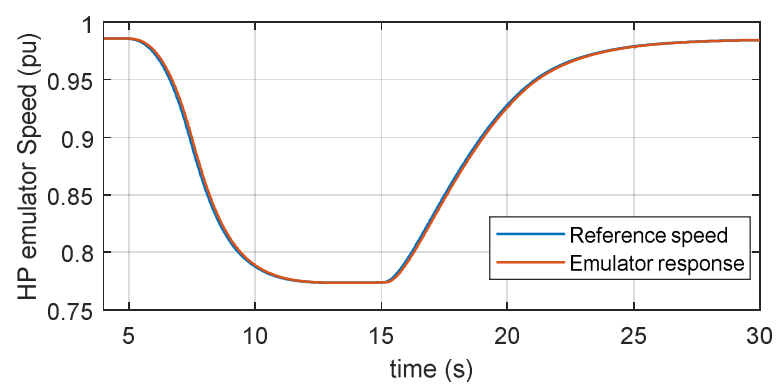

Fig. 8. Speed tracking of HP shaft emulator (engine transient, $m_{t}=1$ )

Fig. 9 shows the IM torque, as a fraction of the rated torque, applied to emulator shaft in order to resemble the engine speed reference.

Fig. 10 shows that PMM q-axis current controller keeping the DC bus voltage at 270 volts during extracting power from HP shaft for the steps of 10 and $20 \mathrm{~kW}$ (shown in Fig. 11).

The power off-take shown in Fig. 10 is simulated during descent phase of the flight at $30000 \mathrm{ft}$ for which the speed tracking of the emulator is shown on Fig. 12. As it can be observed Speed tracking error during power off-take is less than $0.1 \%$.

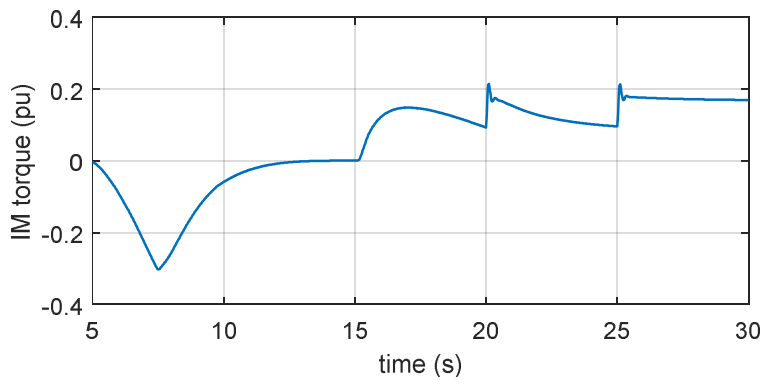

Fig. 9. IM torque (engine transient, $m_{t}=1$ )

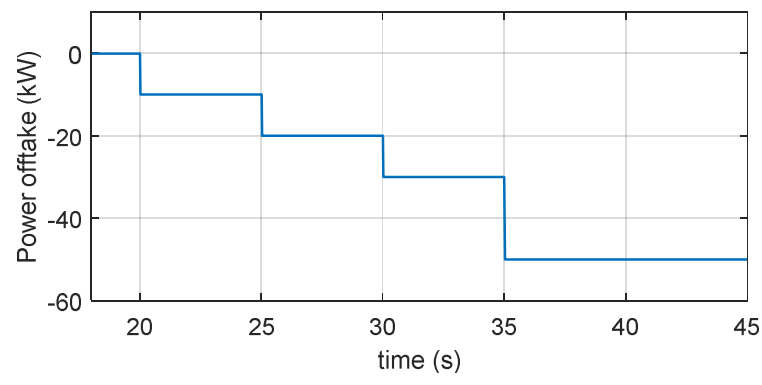

Fig. 10. Power off-take from HP shaft

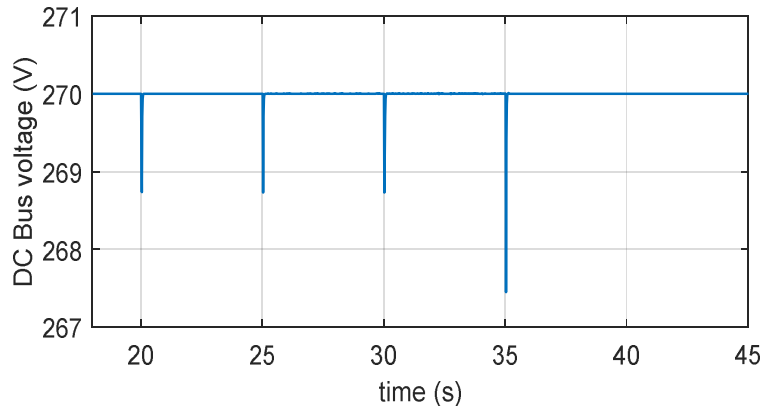

Fig. 11. DC bus voltage during power off-take

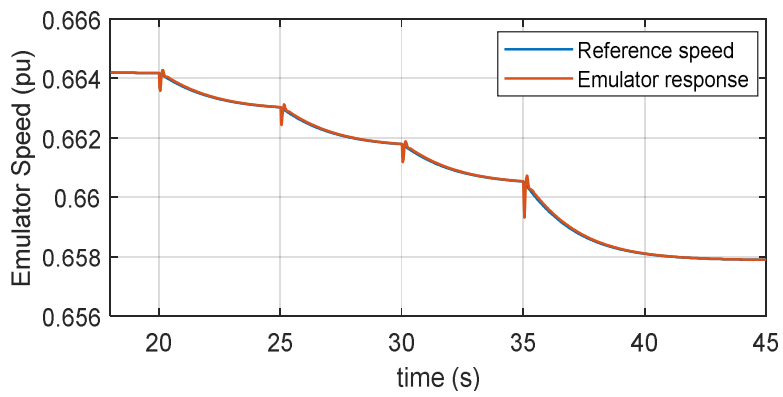

Fig. 12. Speed tracking of the emulator during power off-take

\section{B. Power transfer potential improvements}

Results for a $140 \mathrm{kN}$ thrust turbofan show that depending on the amount of power exchange up to $1 \%$ fuel saving can be achieved for cruise condition, however, suffering the 
penalties for compressor surge margins. Thrust Specific Fuel Consumption (TSFC) is plotted in Fig. 13. Negative power transfer means from HP to LP shaft and positive means from LP to HP shaft and per-unit quantities are fractions of their amount at Maximum Take-Off (MTO) at Sea-Level-Static (SLS).

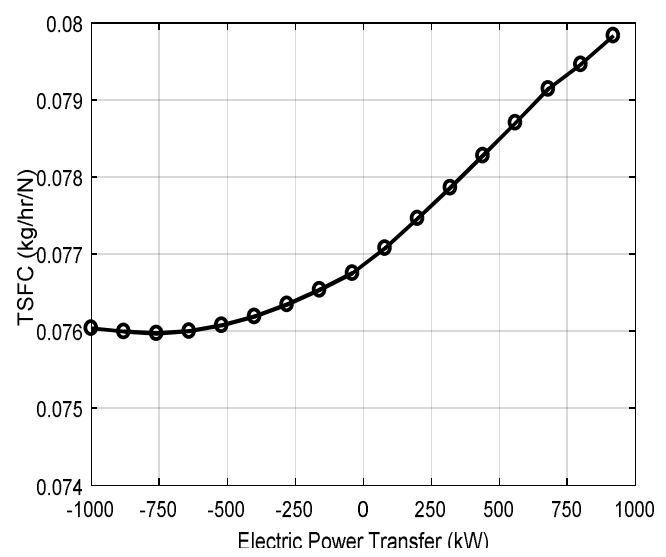

Fig. 13. TSFC (cruise)

While at low speed settings such as ground and flight idle settings, transferring power from LP to HP is favorable in terms of fuel saving shown in Fig. 14 and Fig. 15 for ground and flight idle respectively. For the studied engine, $400 \mathrm{~kW}$ power transfer will decrease the amount of fuel consumption by $33 \%$ and $42 \%$ for ground and flight idle settings respectively. Transferring power from the LP to the HP shaft increases the HPC speed. In this case, HPC can swallow more airflow, which leads to increased surge margin of compressors. In addition the minimum possible idle speed of the engine can be decreased where as a result the excessive thrust at ground idle can be cut down which prevents wearing of the aircraft Wheel brakes. Details regarding compressor surge margins and thrust management are presented in [2].

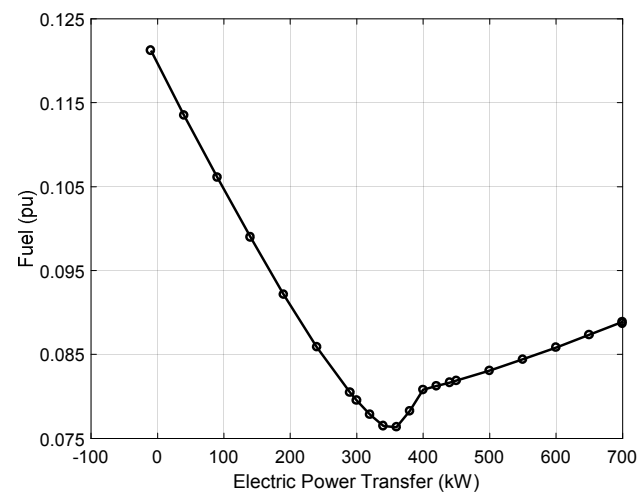

Fig. 14. Fuel consumption (ground idle)

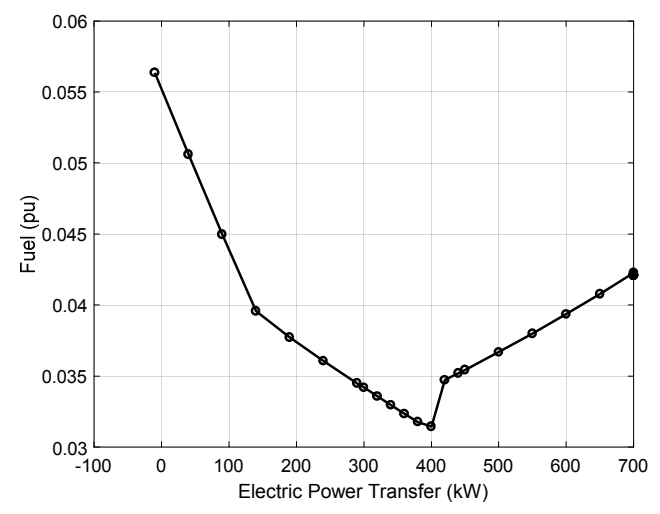

Fig. 15. Fuel consumption (flight idle-20000ft)

\section{Power transfer emulation}

As discussed in section IV, the $500 \mathrm{~kW}$ PM and SR machines are scaled down from $50 \mathrm{~kW}$ ones. In order to emulate the idea of power exchange, the SRM will be in motor mode and PMM will be in generation mode, while the speed of both machines is controlled by the induction machines. Vector control scheme is implemented in order to control the speed of induction machines with bandwidth of $50 \mathrm{~Hz}$. PMM controls the voltage of DC link which is $270 \mathrm{~V}$ according to standard MIL-STD-704F with bandwidth of $100 \mathrm{~Hz}$. For the SRM, a torque control loop determines the amount of torque transfer from the LP to the HP shaft.

Table II shows the design speed of engine and electrical machine shafts.

Table II Design speed of engine and electrical machine shafts

\begin{tabular}{|c|c|c|c|}
\hline & $\begin{array}{c}\text { Engine } \\
(0)\end{array}$ & $\begin{array}{c}500 \mathrm{~kW} \text { machines } \\
(1)\end{array}$ & $\begin{array}{c}50 \mathrm{~kW} \text { machine } \\
(2)\end{array}$ \\
\hline LP (PM) & $4000 \mathrm{rpm}$ & $12000 \mathrm{rpm}$ & $20000 \mathrm{rpm}$ \\
\hline HP (SRM) & $18000 \mathrm{rpm}$ & $18000 \mathrm{rpm}$ & $12000 \mathrm{rpm}$ \\
\hline
\end{tabular}

Accordingly, table III provides the gear ratio between the engine shafts and $500 \mathrm{~kW}$ electrical machine mounted on the engine, $m_{\text {gear }}=\frac{\omega_{1}}{\omega_{0}}$, the speed scale factor from the $500 \mathrm{~kW}$ electrical machine shafts to the PMM and SRM emulator shafts, $m_{\omega}=\frac{\omega_{1}}{\omega_{2}}$ and their torque scale factors, $m_{T}=\frac{T_{1}}{T_{2}}$, from the emulator to the engine for the HP and LP shafts. Considering the amount of power scale from $500 \mathrm{~kW}$ to 50 $\mathrm{kW}$;

$$
\frac{P_{1}}{P_{2}}=\frac{T_{1} \omega_{1}}{T_{2} \omega_{2}}
$$

by using the speed and power data from Table II, $m_{T}$ can be calculated as below,

$$
\begin{array}{ll}
\text { for PMM; } & m_{T}=\frac{T_{1}}{T_{2}}=\frac{500 \mathrm{~kW}}{50 \mathrm{~kW}} \times \frac{20000 \mathrm{rpm}}{12000 \mathrm{rpm}}=16.67 \\
\text { for SRM; } & m_{T}=\frac{T_{1}}{T_{2}}=\frac{500 \mathrm{~kW}}{50 \mathrm{~kW}} \times \frac{12000 \mathrm{rpm}}{18000 \mathrm{rpm}}=6.67
\end{array}
$$


The time scale between the $500 \mathrm{~kW}$ machines and $50 \mathrm{~kW}$ machines is also $m_{t}=1.4$.

Table III Gear and scaling ratios for the LP and HP shafts

\begin{tabular}{|c|c|c|c|}
\hline & $m_{\text {gear }}$ & $m_{w}$ & $m_{T}$ \\
\hline LP (PMM) & 3 & 0.6 & 16.67 \\
\hline HP (SRM) & 1 & 1.5 & 6.67 \\
\hline
\end{tabular}

The simulation block for the gear ratio and scale factors for speed and torque between the engine and the emulator rigs is shown in Fig. 16. A communication delay between the RCP and the emulator drive system has also been considered in the model.

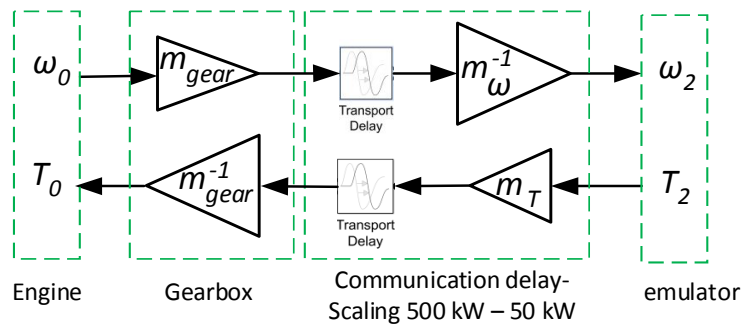

Fig. 16. Speed and torque communication between DSPACE and the emulator rig

The results depicted in Fig. 17 and Fig. 18 are the speed tracking performance of the emulator under rapid acceleration and deceleration of the engine between $50 \%$ and $100 \%$ of throttle.

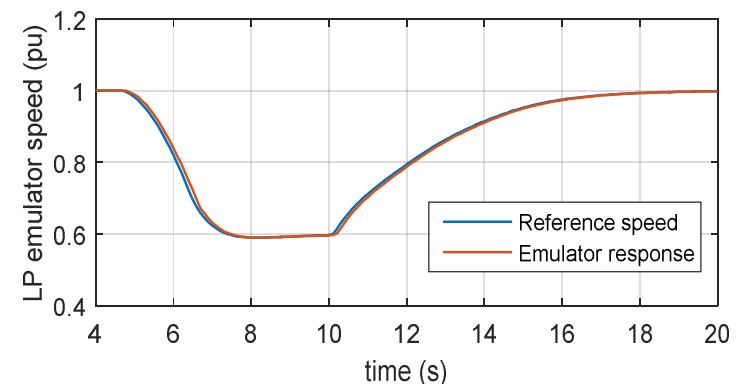

Fig. 17. Speed tracking of LP shaft emulator (engine transient, $m_{t}=1.4$ )

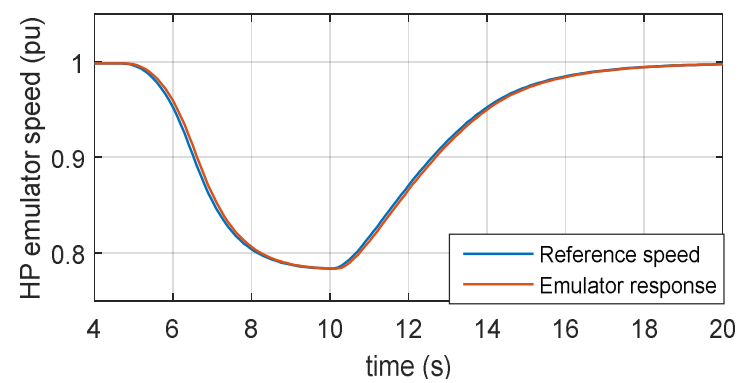

Fig. 18. Speed tracking of HP shaft emulator (engine transient, $m_{t}=1.4$ )

Fig. 19 and Fig. 20 show the IM torques as a fraction of rated torque applied on HP and LP emulator shafts respectively.

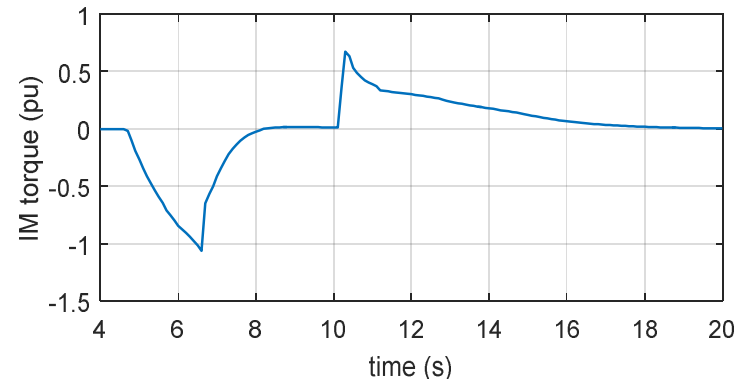

Fig. 19. LP emulator shaft IM torque (engine transient, $m_{t}=1.4$ )

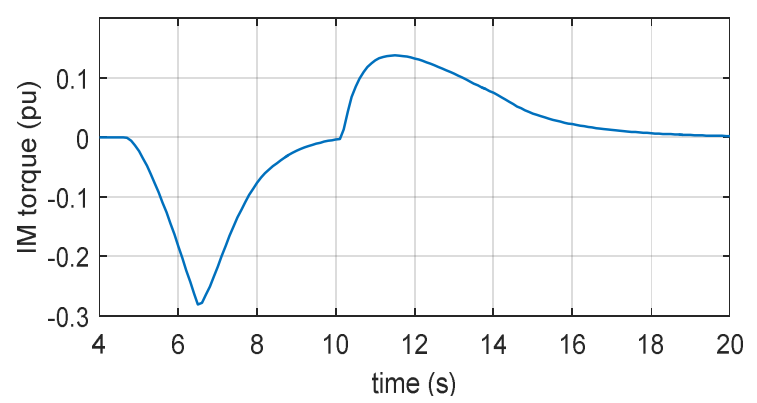

Fig. 20. HP emulator shaft IM torque (engine transient, $m_{t}=1.4$ )

\section{VIII.CONCLUSION}

This paper has introduced an emulator for a turbofan engine which has been designed for use with a future integrated power centre. The emulator system will allow proving the benefits from the implementation of power exchange between the engine shafts. Simulation results of the whole emulation system in MATLAB/SIMULINK environment show that the emulator closely mimics the overall electrical energy generation system under various operating conditions without the need to operate the real engine.

For future work, the engine emulator will be used in conjunction with a programmed aircraft EPS to investigate the engine interactions and control of electric power system, energy storage integration and optimized operation depending on Engine Operating Mode.

\section{ACKNOWLEDGMENT}

This project has received funding from the Clean Sky 2 Joint Undertaking under the European Union's Horizon 2020 research and innovation programme under grant agreement No 807081.

\section{REFERENCES}

[1] M. J. Provost, "The more electric aero-engine: A general overview from an engine manufacturer," International Conference on Power Electronics, Machines and Drives, pp. 246-251, 2002.

[2] H. B. Enalou, S. Bozhko, M. Rashed, and P. Kulsangcharoen, "A Preliminary Study into Turbofan Performance with LP-HP Power Exchange," in GPPS Global Power \& Propulsion Society, Montreal, 2018.

[3] B. A. Correa, Y. Zhang, R. A. Dougal, T. Chiocchio, and K. Schoder, "Mechanical power-hardware-in-the-loop: Emulation of an aeroderivative twin-shaft turbine engine," in 2013 IEEE Electric Ship Technologies Symposium (ESTS), pp. 464-468, 2013. 
[4] M. Bash, M. Boyd, and C. Miller, "Transient Engine Emulation within a Laboratory Testbed for Aircraft Power Systems," SAE International Journal of Aerospace, vol. 7, pp. 191-198, 2014.

[5] C. Gan, R. Todd, and J. Apsley, "Mitigating Time Delays: An Evaluation of Their Impact Using a Simulation Model of an Aircraft Power System Demonstrator Facility," IEEE Industry Applications Magazine, vol. 21, pp. 44-53, 2015.

[6] B. B. Choi and G. Brown, "Propulsion Powertrain Real-Time Simulation Using Hardware-in-the-Loop (HIL) for Aircraft Electric Propulsion System," in 53rd AIAA/SAE/ASEE Joint Propulsion Conference, ed: American Institute of Aeronautics and Astronautics, 2017.

[7] M. Montazeri-Gh and M. Nasiri, "Hardware-in-the-loop simulation for testing of electro-hydraulic fuel control unit in a jet engine application," SIMULATION, vol. 89, pp. 225-233, 2013/02/01 2013.

[8] F. Gao, S. Bozhko, G. Asher, and P. Wheeler, "Comparative Study of Power Sharing Strategies for the DC Electrical Power System in the MEA," 2015.

[9] F. Gao and S. Bozhko, "Modeling and Impedance Analysis of a Single DC Bus-Based Multiple-Source Multiple-Load Electrical Power System," Ieee Transactions on Transportation Electrification, vol. 2, pp. 335-346, Sep 2016.

[10]F. Gao, S. Bozhko, G. Asher, P. Wheeler, and C. Patel, "An Improved Voltage Compensation Approach in a Droop-Controlled DC Power System for the More Electric Aircraft," Ieee Transactions on Power Electronics, vol. 31, pp. 7369-7383, Oct 2016.

[11] V. A. Venikov, Theory of similarity and simulation: with applications to problems in electrical power engineering: Macdonald \& Co., 1969.

[12] S. Bozhko, T. Yang, J. L. Peuvedic, P. Arumugam, M. Degano, A. L. Rocca, et al., "Development of Aircraft Electric Starter-Generator System Based-On Active Rectification Technology," IEEE Transactions on Transportation Electrification, pp. 1-1, 2018

[13]H. B. Enalou, M. Rashed, P. Kulsangcharoen, C. I. Hill, and S. Bozhko, "Nonlinear Aircraft Engine Model for Future Integrated Power Center Development," 2016 International Conference on Electrical Systems for Aircraft, Railway, Ship Propulsion and Road Vehicles \& International Transportation Electrification Conference (Esars-Itec), 2016.

[14]H. B. Enalou, E. A. Soreshjani, M. Rashed, S. S. Yeoh, and S. Bozhko, "A Detailed Modular Governor-Turbine Model for Multiple-Spool Gas Turbine With Scrutiny of Bleeding Effect," Journal of Engineering for Gas Turbines and Power-Transactions of the Asme, vol. 139, Nov 2017. 